\title{
Intrathecal injection of $P / Q$ type voltage-gated calcium channel antibodies from paraneoplastic cerebellar degeneration cause ataxia in mice
}

Elena Martín-García, $\mathrm{PhD}^{1^{*}}$; Francesco Mannara, BSc, ${ }^{2 *}$; Javier Gutiérrez-Cuesta, $\mathrm{PhD}^{1^{*}}$; Lidia Sabater, $\mathrm{PhD}^{2}$; Josep Dalmau, MD, $\mathrm{PhD}^{2,3,4}$; Rafael Maldonado MD, $\mathrm{PhD}^{1}$; and Francesc Graus, $\mathrm{MD}^{2}$.

\section{* Equally contributed to the study}

${ }^{1}$ Laboratori de Neurofarmacologia, Facultat de Ciències de la Salut i de la Vida, Universitat Pompeu Fabra, Barcelona, Spain. ${ }^{2}$ Service of Neurology, Hospital Clínic, Universitat de Barcelona and Institut d'Investigació Biomèdica August Pi i Sunyer (IDIBAPS), Barcelona, Spain; ${ }^{3}$ Institució Catalana de Recerca i Estudis Avançats (ICREA), IDIBAPS, Hospital Clínic, Barcelona, and ${ }^{4}$ Department of Neurology, University of Pennsylvania, Philadelphia, PA, USA.

Correspondence: Francesc Graus, Service of Neurology, Institut d'Investigació Biomèdica August Pi i Sunyer (IDIBAPS). Hospital Clínic, Villarroel 170, Barcelona 08036, Spain. Phone: (34)932275414; Fax: (34)932275783; email: fgraus@clinic.ub.es 


\begin{abstract}
The role of antibodies against the P/Q type voltage-gated calcium channels (VGCC-ab) in the pathogenesis of paraneoplastic cerebellar degeneration (PCD) and lung cancer is unclear. We evaluated in mice the effect of intrathecal injection of IgG purified from serum of a patient with both PCD and Lambert-Eaton myasthenic syndrome (LEMS), and from another patient with isolated LEMS. Mice injected with PCD/LEMS IgG developed marked, reversible ataxia compared with those injected with LEMS or control IgG. These findings suggest that P/Q-type VGCC-ab may play a role in the pathogenesis of ataxia in patients with PCD and SCLC.
\end{abstract}

\title{
Keywords:
}

Paraneoplastic cerebellar degeneration; Lambert-Eaton Myasthenic syndrome; smallcell lung cancer; P/Q-type voltage-gated calcium channel antibodies; intrathecal injection; mouse model. 


\section{Introduction}

Paraneoplastic cerebellar degeneration (PCD) is one of the best characterized paraneoplastic neurological syndromes. Patients with PCD develop a subacute pancerebellar syndrome caused by severe loss of the Purkinje cells of the cerebellum (Graus et al., 2004). Many of them harbor serum and cerebrospinal fluid (CSF) antibodies against different intracellular neuronal antigens depending on the type of underlying tumor that usually are breast, ovary, small-cell lung cancer (SCLC), and Hodgkin lymphoma (Shams'ili et al., 2003). There is no evidence to support that these antibodies, called onconeural antibodies, are pathogenic because the antigen is intracellular and multiple attempts to produce an animal model by passive transfer of patients' IgG or vaccination with the antigens have failed (Carpentier et al., 1998; Graus et al., 1991). Onconeural antibodies probably represent the humoral component of a more complex immune response, likely mediated by cytotoxic T-cell mechanisms against the same onconeural antigens eventually resulting in Purkinje cell death (Darnell and Posner, 2003).

When PCD occurs in association with SCLC, patients develop two clinicalimmunological features that are not seen in other tumor associations. First, up to $25 \%$ of patients with PCD and SCLC show clinical or neurophysiological features of LambertEaton myasthenic syndrome (LEMS), and second, $50 \%$ of them harbor serum and CSF antibodies against P/Q type voltage-gated calcium channels (VGCC-ab) that are highly expressed in the cerebellum and neuromuscular junction (Graus et al., 2002; Mason et al., 1997). The clinical features of LEMS, muscle weakness and autonomic dysfunction, are caused by the antibody binding to $\mathrm{P} / \mathrm{Q}$ type $\mathrm{VGCC}$ at the presynaptic nerve terminals leading to a reduction in neurotransmitter release. However, the role of $\mathrm{P} / \mathrm{Q}$ 
type VGCC-ab in the pathogenesis of PCD is unclear. One possibility is that patients with PCD and P/Q type VGCC-ab develop additional antibodies or T-cell mediated mechanisms that are responsible for the cerebellar symptoms. Alternatively, the P/Q type VGCC-ab of patients with PCD could differ from those found in LEMS in the capacity to alter Purkinje cell function. In the current study we determined if intrathecal injection of IgG from P/Q type VGCC-ab positive patients with SCLC and isolated paraneoplastic LEMS or PCD may produce cerebellar ataxia in mice.

\section{Materials and methods}

2.1 Immunoglobulins.

Serum was obtained from a SCLC patient with PCD/LEMS and VGCC-ab (672 pM/L), another SCLC patient with isolated LEMS and VGCC-ab (708 pM/L), a normal subject (negative control), and a patient with Hodgkin's lymphoma and PCD associated to mGluR1-ab (a gift of Dr. Peter Sillevis-Smitt). Intrathecal injection of purified IgG from the patient with mGluR1-ab has been previously reported to induce transient cerebellar ataxia and it was used as positive control (Sillevis Smitt et al., 2000). The serum of the two patients with SCLC did not have additional antibodies against surface antigens as assessed by immunohistochemistry on paraformaldehyde -fixed frozen rat brain sections, immunoblot of rat cerebellar homogenate, and indirect immunofluorescence on cultures of fetal rat hippocampal neurons, and human embryonic kidney (HEK293) cell line transfected with known surface antigens (NMDA, AMPA, GABA $\mathrm{B}$, mGluR1 and 5 receptors, LGI1, CASPR2, and DPPX), as previously described (Dalmau et al., 2008). Both serum samples had antibodies against the nuclear antigen SOX1 that are markers of the underlying SCLC. SOX1-ab and VGCC-ab frequently associate in patients with LEMS and SCLC (Sabater et al., 2008). The two 
serum samples did not present antibodies against the subunit $\beta 4$ and $\gamma 2$ of VGCC as detected by immunofluorescence on HEK293 cells transfected with the plasmids (MC201619 and SC312948; Origene, Rockville, Maryland, USA). Competitive experiments between the LEMS and the PCD serum could not be done because VGCCab immunoreactivity could not be visualized by indirect immunofluorescence on cultures of fetal rat hippocampal neurons and granular cell neurons (Sabater et al., 2013).

IgG was purified using protein-A Sepharose columns (Pharmacia, Sweden), followed by elution with $\mathrm{Na}$ citrate $(\mathrm{pH}, 2.5)$ and dialysis overnight against phosphate buffered saline (PBS), as reported [3]. The concentration of purified IgG was adjusted to $8-10 \mathrm{mg} / \mathrm{ml}$ and stored at $-70^{\circ} \mathrm{C}$ until use (Table 1$)$.

\subsection{Animal studies}

Animal handling procedures were approved by the Ethical Committee of Pompeu Fabra University of Barcelona and are in accordance with the Directive 86/609/EU of the European Commission. The study was approved by the Ethical Committee of Hospital Clínic. The experimental design is summarized in Table 1. Preliminary experiments included determination of the time and duration of the maximal ataxic behavior after intrathecal injection of $\operatorname{IgG}$ based on the mouse model of cerebellar ataxia postintrathecal injection of mGluR1 IgG (Sillevis Smitt et al., 2000) (data not shown). These studies showed that mice injected with mGluR1 as well as those injected with PCD/LEMS IgG developed transient gait ataxia that peaked between 2 and 4 hours after the intrathecal injection of IgG and resolved at 5 hours.

2.3 Intrathecal injection 
Fourteen weeks-old Swiss/CD1 mice were anesthetized with isoflurane (Abbott-Esteve, Spain) and placed in a stereotaxic frame (Kopf, USA). After identification of the atlanto-occipital membrane a sterile $30 \mathrm{G}$ needle was introduced into the cisterna magna. Cerebrospinal fluid outflow from the injection site confirmed the location, and $10 \mu \mathrm{l}$ of PBS or IgG were slowly injected $(1 \mu \mathrm{l} / \mathrm{min})$. After the procedure, mice were housed individually in standard cages and provided with free access to water and food in a normal 12 hours day/night light cycle environment.

\subsection{Behavioral assessment}

Motor function and behavior were assessed 2 hours after intrathecal injection of IgG or saline following standard protocols as previously described (Filliol et al., 2000). Animals had been handled for 7 days before the experimental procedure and were habituated to the motor paradigm for 2 days before surgery (Table 1).

$\underline{\text { Rotarod }-}$ This test assesses the ability of the mouse to remain on a rotating rod in which the speed of rotation is gradually increased and evaluate general motor coordination. The device is a round drum $(5 \mathrm{~cm}$ diameter $)$ suspended between 2 plexiglas walls. The drum is suspended at $24 \mathrm{~cm}$ from a soft mat covered tabletop. The speed of rotation is controlled by an electric engine with a digital revolution per min (rpm) display. The test consisted in five trial sessions. Each trial started with the mouse being placed on the rotating rod at $4.0 \mathrm{rpm}$, then every 3 seconds the speed increased by $1.0 \mathrm{rpm}$ until $20.0 \mathrm{rpm}$. The trial terminated when the mouse fell from the rod or after 90 seconds, whichever occurred first. There was a 10 seconds interval between trials. Average maximum rotarod speed and time to fall was calculated for each mouse.

Grid walking - Fine motor coordination was evaluated using the grid walking test. Mice had to walk down an alley made up of round metal bars $(2.5 \mathrm{~cm}$ in length, $3 \mathrm{~mm}$ in 
diameter). The bars are spaced at unequal distances $(1,2$, or $3 \mathrm{~cm}$ apart, randomly determined). The grid bars are affixed at their ends to Plexiglas side panels $(25 \mathrm{~cm}$ high). The apparatus is suspended and oriented in a manner that forms a $1 \mathrm{~m}$ long, narrow alley $(2.5 \mathrm{~cm}$ wide) with the animal's home cage placed at the far end. The number of forelimb and hind limb placement errors (foot extends down between missed bars) are measured.

Hanger test - The prehensile reflex was measured using the hanger test, which consists in placing the mouse in the middle of a wire allowed to grip the handle with its forepaws. The prehensile reflex was rated as (0) if the mouse fell off the hanger and as (1) if it remained hanging during a 5 seconds period. During this period traction capacity was rated as (0) if mice did not lifted-up their hind limbs, (1) if they lifted one of the hind limbs, (2) if they lifted both hind limbs, and (3) if they reached one of the ends of the hanger. After this initial evaluation, the latency to fall, time to reach one of the ends of the hanger, as well as the activity performed on the wire was measured in a single trial lasting 60 seconds.

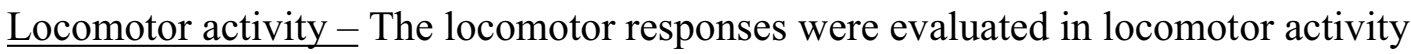
boxes $(9 \times 20 \times 11 \mathrm{~cm}$; Imetronic, Passac, France), equipped with two lines of photocells and placed in a low-luminosity environment (20-25 lux). The locomotor activity was recorded for 10 minutes and 2 variables were measured: horizontal activity ( 1 count $=1$ horizontal displacement from one side to the other of the cage) and vertical activity $(1$ count $=1$ vertical exploration/elevation $)$.

Object-recognition test - The novel object recognition test, conducted in a V-maze, measures short-term memory (Puighermanal et al., 2009). On day 1, before the IgG injection, mice were habituated for 9 minutes to the maze where the task was performed. 24 hours after IgG injection, mice were put back in the maze for 9 minutes, 
two identical objects were presented, and the time that the mice spent exploring each object was recorded. The mice were again placed in the maze 3 hours later for 9 minutes, one of the familiar objects had been replaced with a novel object and the total time spent exploring each of the two objects (novel and familiar) was recorded. Object exploration was defined as the orientation of the nose to the object at a distance of less than $2 \mathrm{~cm}$. A discrimination index (OR index) was calculated as the difference between the times spent exploring either the novel or familiar object divided by the total time exploring the two objects. A higher discrimination index is considered to reflect greater memory retention for the familiar object. The test was repeated 7 and 15 days after intrathecal IgG injection.

\subsection{Statistical analysis}

Statistical analyses were performed using one-way ANOVA between subjects followed by Newman-Keuls post-hoc test when required. Values of $p<0.05$ were considered statistically significant. GraphPad Prism software was used (GraphPad Software, Inc., La Jolla, USA). All results are presented as mean \pm SEM.

\subsection{Neuropathological analysis}

Histological studies were done at several time points after intrathecal injection of IgG or saline to assess the distribution of the injected $\operatorname{IgG}$ and to evaluate potential inflammation or neuronal loss. Due to the limited availability of LEMS serum, a reduced number of animals was used for neurohistopathological analysis and we decided to skip the histopathological analysis at 2 and 24 hours after injection to maximize the number of animals included in the different behavioral paradigms (Table $1)$. 
Mice were sacrificed by an overdose of anesthesia (ketamine and xylazine, 100 and $20 \mathrm{mg} / \mathrm{kg}$ respectively) and perfused through the heart with PBS with $1 \% \mathrm{Na}$ heparin followed by $4 \%$ phosphate-buffered paraformaldehyde. The brain was removed, postfixed by immersion in the same fixative for 4 hours at $4^{\circ} \mathrm{C}$, and snap frozen in isopentane chilled in liquid nitrogen.

To identify the presence of human IgG in mouse brain, frozen sections were air dried for 30 minutes and sequentially incubated with $0.3 \%$ hydrogen peroxide for 10 minutes, $10 \%$ normal goat serum for 20 minutes, biotinylated goat anti-human IgG (Vector Labs, USA) (dilution 1:1000) overnight at $4^{\circ} \mathrm{C}$, and the Vectastain avidin-biotin complex (Vector Labs, USA) for 30 minutes. The substrate staining was developed with $0.05 \%$ diaminobenzidine and $0.01 \%$ hydrogen peroxide.

For histopathological examination, sequential brain sections were stained with hematoxylin and eosin and analyzed by immunohistochemistry for the presence of $\mathrm{T}$ cells (anti-CD3 1:4000, Abcam, Cambridge, UK) and B cells (anti-CD45R/B220, BD Biosciences, Pharrmingen, San Diego, CA), changes in astrocytes (anti-GFAP, 1/10000, Sigma- Aldrich, St. Louis, MO) or microglia (Iba-1, 1:500, Wako Chemicals, Burlingame VA), and neuronal apoptosis (anti-caspase-3-cleaved, 1:200, Cell Signalling Techology, Danvers MA). After primary antibody incubation, all sections (frozen or paraffin-embedded) were incubated at room temperature for 30 minutes with the appropriate biotinylated secondary antibody and the Vectastain avidin-biotin complex (Vector Labs, USA) as described (Bernal et al., 2002).

\section{Results}

\subsection{Motor evaluation}


Mice injected with IgG from the normal subject or the patient with LEMS performed similar motor responses to those injected with saline on the accelerated rotarod test done 2 hours after the intrathecal injection. In contrast, mice injected with IgG from the PCD/LEMS patient showed motor impairment in the same range that mice injected with mGluR1 IgG (Figure 1 and Table 2).

To confirm that the poor motor performance in the rotarod test was due to a problem of fine motor coordination, mouse behavioral responses were evaluated in the grid walking test. Mice injected with the PCD/LEMS IgG or the mGluR1 IgG showed significant performance impairment in comparison to the other groups, as shown in Figure 2 and by the one-way ANOVA resumed in Table 2.

To make sure that motor disturbance was due to cerebellar dysfunction, and not to muscle weakness or reduced motor activity, we performed the hanger and the locomotor activity tests. No significant difference among all groups of animals was observed in these two behavioral models, indicating that the findings were due to impairment in motor coordination without changes in other relevant motor responses (Figure 3 and Table 2).

\subsection{Short-term memory analysis}

The object recognition test performed 24 hours after intrathecal injection of $\operatorname{IgG}$ demonstrated a poorer performance of all mice injected with any type of IgG compared with those injected with saline. In addition, mice injected with PCD/LEMS IgG or mGluR1 IgG showed a more severe short-term memory impairment than mice injected with control IgG or LEMS IgG. These differences remained significant 7 days after IgG injection (Figure 4 and Table 2) and disappeared in the test performed 15 days after 
injection, when all mice, including those injected with saline, performed similarly (data not shown).

\subsection{Neuropathological analysis}

The histological study of the brain of mice sacrificed 2 hours after intrathecal injection of $\mathrm{IgG}$ showed that IgG distribution was similar in all the groups. The IgG was diffusely distributed over the cortex of the cerebellum and also reached the superficial layers of the cerebral cortex, and posterior part of the medulla oblongata (Figure 5). In the cerebellum, IgG immunoreactivity was observed in the neuropil of the molecular layer, cytoplasm of Purkinje cells and granular cell layer (Figure 6). In brains examined 24 hours after the intrathecal injection, IgG immunoreactivity was predominantly confined in the cytoplasm of microglial cells (Figure 7) that were identified by their characteristic morphology and immunoreactivity with the microglial marker Iba1(data not shown). In addition, the cytoplasm of a few Purkinje cells and other neurons of the cerebral cortex and brainstem also showed $\operatorname{IgG}$ immunoreactivity. Histopathological analysis at 24 hours and 15 days did not reveal neuronal loss, apoptotic neurons, inflammation or astrogliosis in any of the mice injected with the different types of IgG (data not shown).

\section{Discussion}

This study demonstrates for the first time that intrathecal injection of IgG from a patient with PCD/LEMS and P/Q-type VGCC-ab causes cerebellar ataxia in mice, whereas the IgG from a patient with isolated LEMS and similar titers of P/Q-type VGCC-ab did not produce any effect in our behavioral models. Although the neuropathological analysis revealed that the IgG injected into the cisterna magna diffused beyond the cerebellum, 
the results in the battery of motor tests revealed impairment in motor coordination that was consistent with cerebellar dysfunction. The normal performance of mice in the hanger and locomotor activity tests reasonably rule out that the motor coordination abnormalities observed in the rotarod and grid tests were cause by muscular weakness or decreased motor activity. The severity and the temporal profile of this impairment in motor coordination were similar to that observed when animals were injected with mGluR1 IgG, which is a previously validated model of antibody-mediated ataxia (Sillevis Smitt et al., 2000). The resolution of the cerebellar effects several hours after the $\mathrm{IgG}$ injection is probably explained by the $\mathrm{IgG}$ removal by the microglia as demonstrated in the histological studies done 24 hours after the intrathecal injection of the IgG and the normal turnover of CSF proteins.

Ataxic mice also showed, in our experimental conditions, a profound impairment of the spatial short-term memory as measured in the object-recognition test. We included the object-recognition test in our behavioral battery of evaluation due to the well known impact of cerebellum in cognition and the experimental evidence that cerebellar damage may cause a cognitive deficit independently of fine motor control (Lalonde and Strazielle, 2003; Stoodley, 2012). Surprisingly, the memory impairments persisted one week after the $\operatorname{IgG}$ injections. The reason for the persistence of the memory deficits when the motor coordination effects lasted only a few hours remains unclear. However, our findings support the interest of including cognitive tests in similar studies that evaluate the effect of specific antibodies on cerebellar function.

The frequency of P/Q-type VGCC-ab in patients with PCD and SCLC is much higher than that expected by the presence of the underlying tumor (41\% vs. $5 \%)$ and suggests that the antibodies are not merely markers of the SCLC (Graus et al., 2002; Monstad et al., 2004). Although this finding could be explained by the elevated 
frequency of concomitant LEMS (Clouston et al., 1992), P/Q-type VGCC-ab are present in PCD patients without clinical nor neurophysiological evidence of LEMS (Graus et al., 2002) rising the question on the potential role of VGCC-ab in the pathogenesis of the cerebellar ataxia. One of the most plausible explanations is that in contrast to LEMS, the distinct epitope repertoire of P/Q-type VGCC-ab in patients with PCD and SCLC favors the inhibition of VGCC's function in the cerebellum.

We cannot completely rule out that the IgG of the patient with PCD/LEMS caused the cerebellar ataxia due to the presence of additional antibodies against other neuronal surface antigens. However, our studies on ex vivo neurons and HEK cells transfected with plasmids of known surface antigens failed to show other antibodies in the serum of the patients, including those against the receptor of $\mathrm{GABA}_{\mathrm{B}}$, commonly found in patients with limbic encephalitis, and SCLC or CASPR2 described in patients with non paraneoplastic cerebellar ataxia (Becker et al., 2012; Boronat et al., 2011). In addition, we have not identified antibodies against characterized surface antigens other than the P/Q-type VGCC-ab on a series of 39 patients with PCD and SCLC (Sabater et al., 2013).

The alternative explanation for the differential effect on cerebellar function in our study is that the P/Q-type VGCC-ab of the patient with PCD-LEMS recognized specific subunits or epitopes critical for the function of VGCC in the cerebellum. The samples used in this study did not react with $\beta 4$ or $\gamma 2$, which are VGCC subunits that are preferentially expressed in the cerebellum (Black, 2003; Ludwig et al., 1997). Antibodies raised against the extracellular part of the S5-S6 linker segments in domain III of the mouse $\alpha 1$ A subunit of P/Q-type VGCC (Mori et al., 1991) were reported to impair synaptic transmission in cerebellar slices and to cause cerebellar ataxia in mice in which the antibody was infused during 3 days in the posterior fossa (Liao et al., 
2008). However, these effects on cerebellum were not reproduced when rats were immunized with multiple intradermally injections of the domain III peptide. Immunized rats developed P/Q-type VGCC-ab but only 6 of 10 showed mild muscle weakness and none developed cerebellar ataxia, although no specific tests were conducted to detect mild cerebellar dysfunction (Komai et al., 1999). P/Q-type VGCC-ab from patients with isolated LEMS do not recognize the domain III S5-S6 epitope (Parsons and Kwok, 2002; Takamori et al., 1997). Whether this epitope is recognized by P/Q-type VGCC-ab of patients with PCD is presently unknown.

Despite P/Q-type VGCC-ab with a particular epitope repertoire may be relevant in the pathogenesis of PCD, it remains unclear why the ataxia does not usually respond to the immunotherapy and the mechanism of the Purkinje cell loss found in postmortem studies (Blumenfeld et al., 1991;Fukuda et al., 2003;Goldstein et al., 1994). A similar situation occurs in patients with glutamic acid decarboxylase (GAD)-ab. Patients with high titers of GAD-ab may develop stiff-man syndrome or cerebellar ataxia and postmortem studies show neuronal loss only in those with cerebellar ataxia (Ishida et al., 2007; Saiz et al., 2008). Taken together, these data suggest that when antibodies target cerebellar antigens, the functional impairment of the synaptic activity may lead to irreversible neuronal loss, a feature that is uncommon in other antibody-mediated neurological syndromes probably also mediated by antibodies targeting brain areas different from the cerebellum. 


\section{References}

Becker, E.B., Zuliani, L., Pettingill, R., Lang, B., Waters, P., Dulneva, A., Sobott, F., Wardle, M., Graus, F., Bataller, L., Robertson, N.P., Vincent, A.,2012. Contactinassociated protein-2 antibodies in non-paraneoplastic cerebellar ataxia. J. Neurol. Neurosurg. Psychiatry. 83, 437-440.

Bernal, F., Graus, F., Pifarre, A., Saiz, A., Benyahia, B., Ribalta, T.,2002. Immunohistochemical analysis of anti-Hu-associated paraneoplastic encephalomyelitis. Acta Neuropathol. 103, 509-515.

Black, J.L.,3rd,2003. The voltage-gated calcium channel gamma subunits: a review of the literature. J. Bioenerg. Biomembr. 35, 649-660.

Blumenfeld, A.M., Recht, L.D., Chad, D.A., DeGirolami, U., Griffin, T., Jaeckle, K.A.,1991. Coexistence of Lambert-Eaton myasthenic syndrome and subacute cerebellar degeneration: differential effects of treatment. Neurology. 41, 1682-1685.

Boronat, A., Sabater, L., Saiz, A., Dalmau, J., Graus, F.,2011. GABA(B) receptor antibodies in limbic encephalitis and anti-GAD-associated neurologic disorders. Neurology. 76, 795-800.

Carpentier, A.F., Rosenfeld, M.R., Delattre, J.Y., Whalen, R.G., Posner, J.B., Dalmau, J.,1998. DNA vaccination with HuD inhibits growth of a neuroblastoma in mice. Clin. Cancer Res. 4, 2819-2824.

Clouston, P.D., Saper, C.B., Arbizu, T., Johnston, I., Lang, B., Newsom-Davis, J., Posner, J.B.,1992. Paraneoplastic cerebellar degeneration. III. Cerebellar degeneration, cancer, and the Lambert-Eaton myasthenic syndrome. Neurology. 42, 1944-1950. 
Dalmau, J., Gleichman, A.J., Hughes, E.G., Rossi, J.E., Peng, X., Lai, M., Dessain, S.K., Rosenfeld, M.R., Balice-Gordon, R., Lynch, D.R.,2008. Anti-NMDA-receptor encephalitis: case series and analysis of the effects of antibodies. Lancet Neurol. 7, 1091-1098.

Darnell, R.B., Posner, J.B.,2003. Paraneoplastic syndromes involving the nervous system. N. Engl. J. Med. 349, 1543-1554.

Filliol, D., Ghozland, S., Chluba, J., Martin, M., Matthes, H.W., Simonin, F., Befort, K., Gaveriaux-Ruff, C., Dierich, A., LeMeur, M., Valverde, O., Maldonado, R., Kieffer, B.L.,2000. Mice deficient for delta- and mu-opioid receptors exhibit opposing alterations of emotional responses. Nat. Genet. 25, 195-200.

Fukuda, T., Motomura, M., Nakao, Y., Shiraishi, H., Yoshimura, T., Iwanaga, K., Tsujihata, M., Eguchi, K.,2003. Reduction of P/Q-type calcium channels in the postmortem cerebellum of paraneoplastic cerebellar degeneration with Lambert-Eaton myasthenic syndrome. Ann. Neurol. 53, 21-28.

Goldstein, J.M., Waxman, S.G., Vollmer, T.L., Lang, B., Johnston, I., Newsom-Davis, J.,1994. Subacute cerebellar degeneration and Lambert-Eaton myasthenic syndrome associated with antibodies to voltage-gated calcium channels: differential effect of immunosuppressive therapy on central and peripheral defects. J. Neurol. Neurosurg. Psychiatry. 57, 1138-1139.

Graus, F., Illa, I., Agusti, M., Ribalta, T., Cruz-Sanchez, F., Juarez, C.,1991. Effect of intraventricular injection of an anti-Purkinje cell antibody (anti-Yo) in a guinea pig model. J. Neurol. Sci. 106, 82-87. 
Graus, F., Lang, B., Pozo-Rosich, P., Saiz, A., Casamitjana, R., Vincent, A.,2002. P/Q type calcium-channel antibodies in paraneoplastic cerebellar degeneration with lung cancer. Neurology. 59, 764-766.

Graus, F., Delattre, J.Y., Antoine, J.C., Dalmau, J., Giometto, B., Grisold, W., Honnorat, J., Smitt, P.S., Vedeler, C., Verschuuren, J.J., Vincent, A., Voltz, R.,2004. Recommended diagnostic criteria for paraneoplastic neurological syndromes. J. Neurol. Neurosurg. Psychiatry. 75, 1135-1140.

Ishida, K., Mitoma, H., Wada, Y., Oka, T., Shibahara, J., Saito, Y., Murayama, S., Mizusawa, H.,2007. Selective loss of Purkinje cells in a patient with anti-glutamic acid decarboxylase antibody-associated cerebellar ataxia. J. Neurol. Neurosurg. Psychiatry. 78, 190-192.

Komai, K., Iwasa, K., Takamori, M.,1999. Calcium channel peptide can cause an autoimmune-mediated model of Lambert-Eaton myasthenic syndrome in rats. J. Neurol. Sci. $166,126-130$.

Lalonde, R., Strazielle, C.,2003. The effects of cerebellar damage on maze learning in animals. Cerebellum. 2, 300-309.

Liao, Y.J., Safa, P., Chen, Y.R., Sobel, R.A., Boyden, E.S., Tsien, R.W.,2008. Anti$\mathrm{Ca} 2+$ channel antibody attenuates $\mathrm{Ca} 2+$ currents and mimics cerebellar ataxia in vivo. Proc. Natl. Acad. Sci. U. S. A. 105, 2705-2710.

Ludwig, A., Flockerzi, V., Hofmann, F.,1997. Regional expression and cellular localization of the alphal and beta subunit of high voltage-activated calcium channels in rat brain. J. Neurosci. 17, 1339-1349. 
Mason, W.P., Graus, F., Lang, B., Honnorat, J., Delattre, J.Y., Valldeoriola, F., Antoine, J.C., Rosenblum, M.K., Rosenfeld, M.R., Newsom-Davis, J., Posner, J.B., Dalmau, J.,1997. Small-cell lung cancer, paraneoplastic cerebellar degeneration and the LambertEaton myasthenic syndrome. Brain. 120, 1279-1300.

Monstad, S.E., Drivsholm, L., Storstein, A., Aarseth, J.H., Haugen, M., Lang, B., Vincent, A., Vedeler, C.A.,2004. Hu and voltage-gated calcium channel (VGCC) antibodies related to the prognosis of small-cell lung cancer. J. Clin. Oncol. 22, 795800.

Mori, Y., Friedrich, T., Kim, M.S., Mikami, A., Nakai, J., Ruth, P., Bosse, E., Hofmann, F., Flockerzi, V., Furuichi, T.,1991. Primary structure and functional expression from complementary DNA of a brain calcium channel. Nature. 350, 398-402.

Parsons, K.T., Kwok, W.W.,2002. Linear B-cell epitopes in Lambert-Eaton myasthenic syndrome defined by cell-free synthetic peptide binding. J. Neuroimmunol. 126, 190195.

Puighermanal, E., Marsicano, G., Busquets-Garcia, A., Lutz, B., Maldonado, R., Ozaita, A.,2009. Cannabinoid modulation of hippocampal long-term memory is mediated by mTOR signaling. Nat. Neurosci. 12, 1152-1158.

Sabater, L., Titulaer, M., Saiz, A., Verschuuren, J., Gure, A.O., Graus, F.,2008. SOX1 antibodies are markers of paraneoplastic Lambert-Eaton myasthenic syndrome. Neurology. 70, 924-928.

Sabater, L., Hoftberger, R., Boronat, A., Saiz, A., Dalmau, J., Graus, F.,2013. Antibody repertoire in paraneoplastic cerebellar degeneration and small cell lung cancer. PLoS One. 8, e60438. 
Saiz, A., Blanco, Y., Sabater, L., Gonzalez, F., Bataller, L., Casamitjana, R., RamioTorrenta, L., Graus, F.,2008. Spectrum of neurological syndromes associated with glutamic acid decarboxylase antibodies: diagnostic clues for this association. Brain. $131,2553-2563$.

Shams'ili, S., Grefkens, J., de Leeuw, B., van den Bent, M., Hooijkaas, H., van der Holt, B., Vecht, C., Sillevis Smitt, P.,2003. Paraneoplastic cerebellar degeneration associated with antineuronal antibodies: analysis of 50 patients. Brain. 126, 1409-1418.

Sillevis Smitt, P., Kinoshita, A., De Leeuw, B., Moll, W., Coesmans, M., Jaarsma, D., Henzen-Logmans, S., Vecht, C., De Zeeuw, C., Sekiyama, N., Nakanishi, S., Shigemoto, R.,2000. Paraneoplastic cerebellar ataxia due to autoantibodies against a glutamate receptor. N. Engl. J. Med. 342, 21-27.

Stoodley, C.J.,2012. The cerebellum and cognition: evidence from functional imaging studies. Cerebellum. 11, 352-365.

Takamori, M., Iwasa, K., Komai, K.,1997. Antibodies to synthetic peptides of the alpha1A subunit of the voltage-gated calcium channel in Lambert-Eaton myasthenic syndrome. Neurology. 48, 1261-1265. 


\section{Acknowledgements}

The authors thank Mrs. Mercè Alba, Mrs. Eva Caballero, and Mr. Javier Gimeno-Bayón for technical assistance. Dr. Santiago Rojas for surgical procedure suggestions and Dr. Peter Sillevis-Smitt for providing the positive mGluR1 positive serum. This study was supported in part by grants PS09/0193 (FG) PS11/01780 (JD) Fondo de Investigaciones Sanitarias, Madrid, grant from Fundació la Marató de TV3 (JD), Barcelona, grants from the “Ministerio de Ciencia e Innovación”, (SAF2007-64062), and “'Instituto de Salud Carlos III”' (RETICS-Red de Trastornos Adictivos-Redes Temáticas de Investigación Cooperativa en Salud: RD06/0001/0001, RD06/0001/1004) (RM), Spain. The parcial support of FEDER funds (EU) is also acknowledged. 


\section{Legend of Figures}

\section{Figure 1}

Average speed on the rotating bar when mice fell from the rod during the rotarod test. The normal human serum (NHS) IgG, the LEMS IgG, and the saline group reached a significantly higher speed compared to that of mGluR1 IgG and PCD/LEMS IgG group, indicating that these two groups showed less general motor coordination. ${ }^{* * *}: \mathrm{p}<0.001$ compared to NHS IgG group; $\bullet \bullet: p<0.001$ compared to LEMS IgG group.

\section{Figure 2}

Number of slides counted during the grid test performances. Number of slides was significantly higher in the mGluR1 IgG and PCD/LEMS IgG groups compared to normal human serum (NHS) IgG and LEMS IgG groups. ***: $\mathrm{p}<0.001$ compared to NHS IgG group; $\bullet: \mathrm{p}<0.05$, and $\bullet \bullet: \mathrm{p}<0.01$ compared to the LEMS IgG group.

\section{Figure 3}

No differences observed among groups in the prehensile reflex (A), horizontal activity (B) and vertical activity $(\mathrm{C}) .(\mathrm{B}, \mathrm{C})$ : vertical bars represent the number of horizontal or vertical explorations recorded by the photocells. NHS: normal human serum.

\section{Figure 4}

OR index calculated during the $\mathrm{V}$-maze object recognition trials 24 hours (A) and 7 days (B). The higher the OR index, the more severe is the underlying short-term memory. At 24 hours, all groups injected with IgG performed worse than the saline group (\#\#: $p<0.01$ normal humas serum (NHS) IgG compared to saline group). However, the mGluR1 IgG and the PCD/LEMS IgG groups showed more severe memory impairment when compared to the NHS $\operatorname{IgG}(* *, p<0.01, * * *, p<0.001)$ or to the LEMS IgG groups $(\bullet, p<0.01, \cdots, p<0.001)$. 


\section{Figure 5}

Sagittal brain section of a mouse sacrificed 2 hours after intrathecal injection of IgG from the PCD/LEMS patient. IgG deposits detected by a biotinylated anti-human IgG antibody. There is a robust immunolabeling of IgG in the cerebellum, except in the deepest region. There is also IgG reactivity in the posterior aspect of lower brainstem and external aspects of cerebral hemispheres. Rod indicated site of injection.

\section{Figure 6}

Cerebellar section of mice sacrificed 2 hours after intrathecal injection of saline (D) or normal human serum IgG (A), mGluR1 IgG (B), and PCD/LEMS IgG. IgG deposits detected by a biotinylated anti-human IgG antibody. All mice injected with IgG showed robust immunolabeling of IgG in the three layers of the cerebellum. All sections mildly countersained with hematoxylin. Magnification bar $1000 \mu \mathrm{m}$.

\section{Figure 7}

Cerebellar section of mice sacrificed 24 hours after intrathecal injection of saline (D) or normal human serum IgG (A), mGluR1 IgG (B), and PCD/LEMS IgG. IgG deposits detected by a biotinylated anti-human IgG antibody. All mice injected with IgG showed IgG immunolabeling of microglial cells identified by the characteristic morphology and labeling with the microglial marker anti-Iba1 (not shown). In addition, a few Purkinje cells present IgG reactivity in the cytoplasm. All sections mildly countersained with hematoxylin. Magnification bar $1000 \mu \mathrm{m}$. 


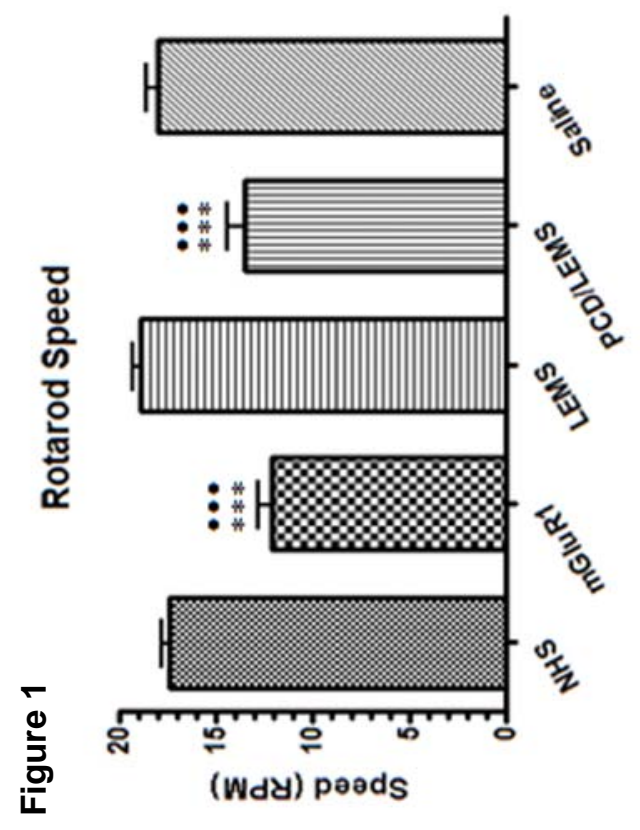




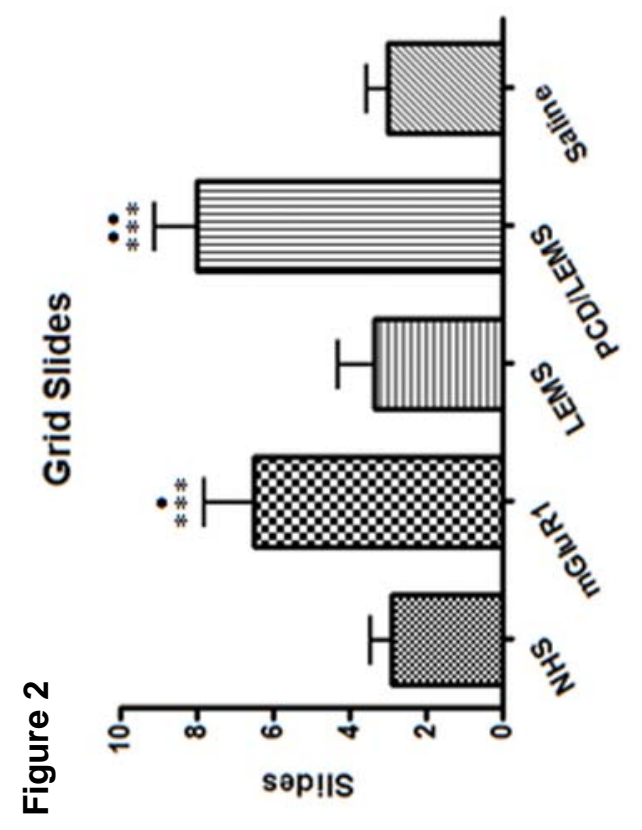


Figyre 3 Hanger test: Prehensile Reflex

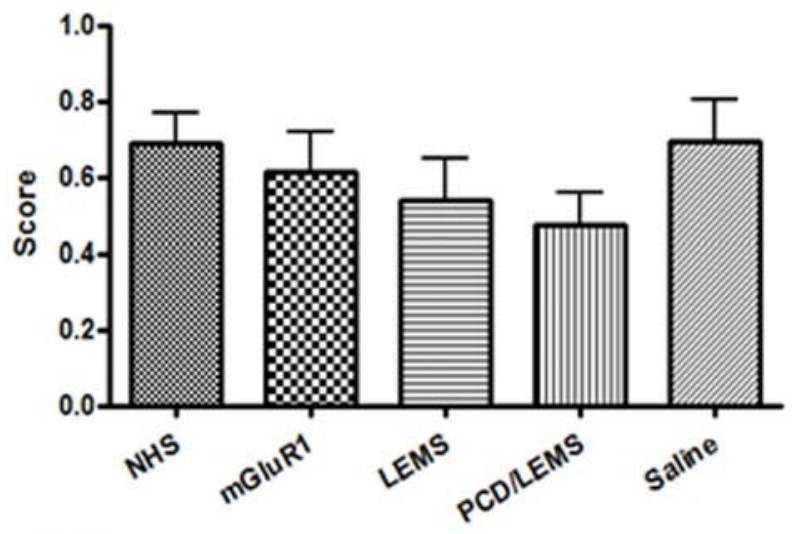

$B$ Horizontal Activity
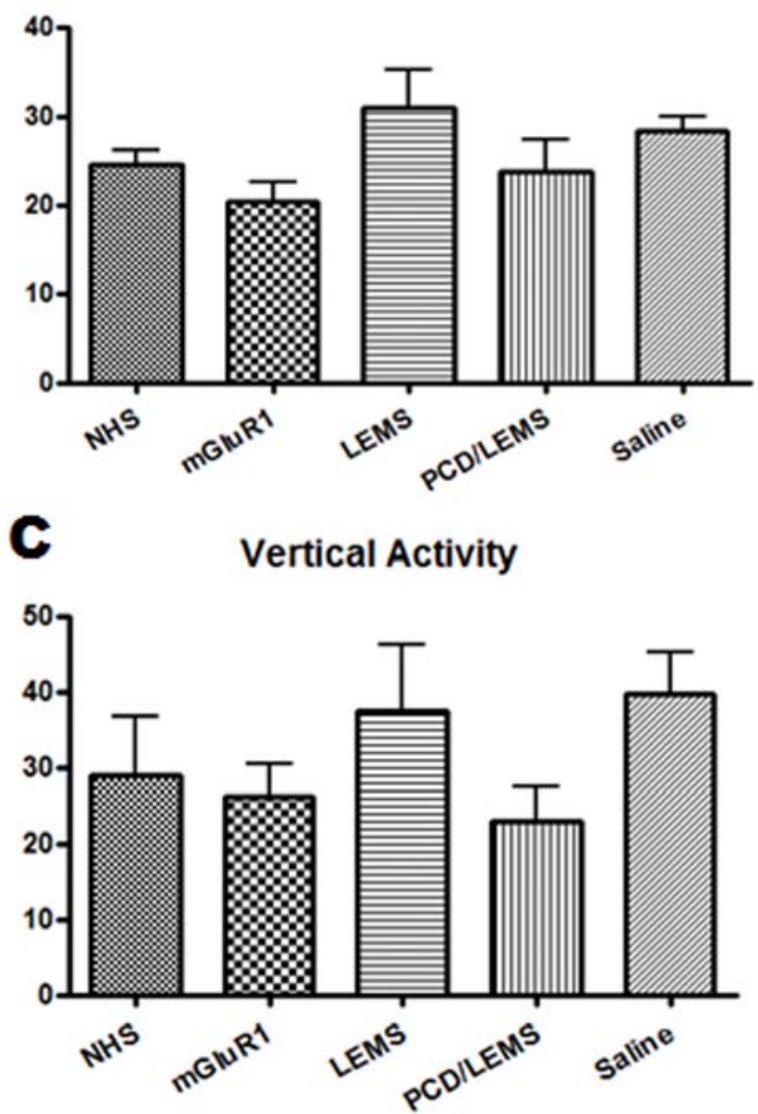
Figure 4

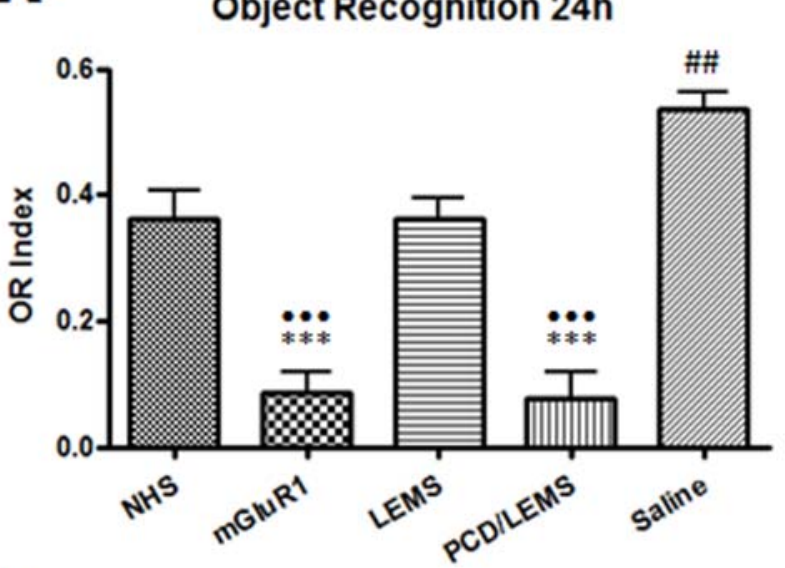

B

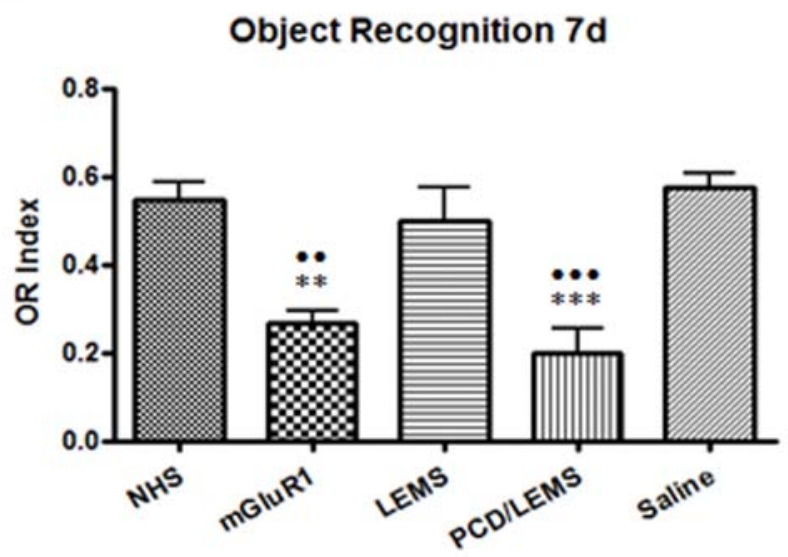




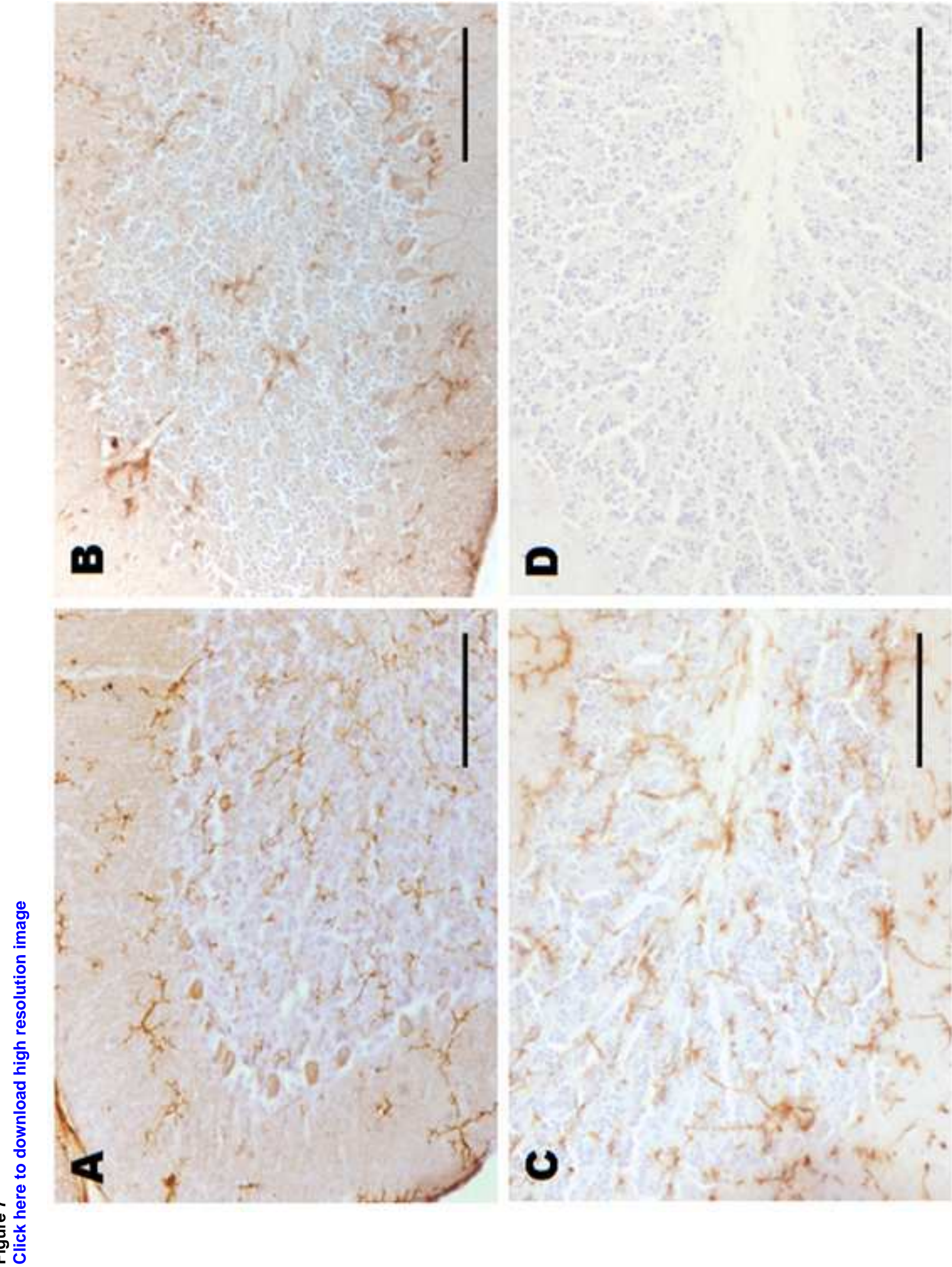
Table 1. Experimental design

\begin{tabular}{|c|c|c|c|}
\hline Sample (mg/ml) & $\begin{array}{l}\text { Motor behavior } \\
\text { tests at } 2 \text { hours* }\end{array}$ & $\begin{array}{l}\text { Object-recognition task } \\
\text { Time in days (mice \#) }\end{array}$ & $\begin{array}{l}\text { Histological analysis } \\
\text { Time (mice \#) }{ }^{\dagger}\end{array}$ \\
\hline Saline & 14 & $1 \mathrm{~d}(12), 7 \mathrm{~d}(10), 15 \mathrm{~d}(8)$ & $2 \mathrm{~h} \mathrm{(2),} \mathrm{24h} \mathrm{(2),} \mathrm{15d} \mathrm{(2)}$ \\
\hline Control IgG (9.2) & 16 & $1 \mathrm{~d}(14), 7 \mathrm{~d}(12), 15 \mathrm{~d}(10)$ & 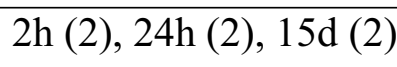 \\
\hline mGluR1 IgG (9.4) & 12 & $1 \mathrm{~d}(10), 7 \mathrm{~d}(8), \quad 15 \mathrm{~d}(6)$ & $2 \mathrm{~h}(2), 24 \mathrm{~h}(2), 15 \mathrm{~d}(2)$ \\
\hline LEMS IgG (9.8) & 8 & $1 \mathrm{~d}(8), 7 \mathrm{~d}(8), \quad 15 \mathrm{~d}(8)$ & $2 \mathrm{~h}(0), 24 \mathrm{~h}(0), 15 \mathrm{~d}(2)$ \\
\hline PCD/LEMS IgG (8.6) & 12 & $1 \mathrm{~d}(10), 7 \mathrm{~d}(8), \quad 15 \mathrm{~d}(6)$ & $2 \mathrm{~h} \mathrm{(2),} \mathrm{24h} \mathrm{(2),} \mathrm{15d} \mathrm{(2)}$ \\
\hline
\end{tabular}

*Rotarod test, Grid test, Hanger test, Locomotor/vertical activity test. Number indicates mice evaluated in each test. $\uparrow$ Histological analysis not performed at 2 and 24 hours in the LEMS IgG group to maximize the statistical $\mathrm{N}$ for all the tests 
Table 2. Motor coordination and cognitive test: one-way ANOVA results

\begin{tabular}{|l|l|l|}
\hline \multirow{2}{*}{} & \multicolumn{2}{|c|}{ Group as between-subjects factor } \\
\cline { 2 - 3 } & \multicolumn{1}{|c|}{ F-value } & \multicolumn{1}{c|}{ P-value } \\
\hline Rotarod: speed & $F_{(4,57)}=22.07$ & $P<0.001$ \\
\hline Grid test: number of slids & $F_{(4,57)}=6.94$ & $P<0.001$ \\
\hline Hanger test: prehensile reflex score & $F_{(4,57)}=1.05$ & n.s. \\
\hline Horizontal activity & $F_{(4,56)}=2.35$ & n.s. \\
\hline Vertical activity & $F_{(4,57)}=1.17$ & $n . s$. \\
\hline Object recognition index 24 hours & $F_{(4,49)}=26.87$ & $P<0.001$ \\
\hline Object recognition index 7 days & $F_{(4,33)}=10.86$ & $P<0.001$ \\
\hline
\end{tabular}

One-way ANOVA with group (normal human serum (NHS) IgG, mGluR1 IgG,

LEMS IgG, PCD/LEMS IgG and saline) as between-subjects factor; n.s.: not significant 